\title{
Population prevalence of congenital disabilities among children aged 0-2 years resident in urban slums of Pune, India
}

\author{
Humaira Ansari ${ }^{1} *$ (D) \\ Received: 2 Apr 2019 \\ Published: 15 Sep 2021
}

\begin{abstract}
Background: Non-fatal birth defects and developmental disabilities are the most important causes of congenital disabilities in young children. This study was performed to determine the prevalence of congenital disabilities among children aged 0-2 years resident in urban slums of Pune.

Methods: In 2016, using a random sampling method, 840 children from 28 registered slums located in each of the 14 wards of Pune city, India, were included in the study. Data on congenital disabilities and the clinical diagnosis responsible for the disability were collected. Data were also collected on selected risk factors for these conditions and current treatment through a structured questionnaire. Descriptive analysis was used to describe relationships among variables. Pearson's chi-square test was used to determine associations, and the level of significance was established at $\mathrm{P}<0.05$. Associations between outcomes of interest and risk factors were expressed as Odds Ratios (OR) at 95\% Confidence Interval (CI).

Results: In this age group, the prevalence of congenital disability was $1.67 \%$ (95\% CI $0.91-2.78)(14 / 840)$. The prevalence of clinically diagnosed birth defects was $1.19 \%(95 \%$ CI $0.57-2.18)(10 / 840)$. The prevalence of developmental disabilities was $0.48 \%$ (95\% CI 0.13-1.21) (4/840). Children with birth defects were more likely to be premature $(\mathrm{P}=0.045, \mathrm{OR}=4.34,95 \% \mathrm{CI}=1.03-18.28)$ and low birth weight $(\mathrm{P}=0.003, \mathrm{OR}=10.41,95 \% \mathrm{CI}=2.21-48.38)$. Only seven out of 14 children with birth defects and developmental disabilities were taken for treatment after the initial diagnosis.

Conclusion: Birth defects and developmental disabilities are prevalent conditions. Community awareness, provision of appropriate medical and habilitation care, as well as screening and early intervention for these conditions are essential to prevent morbidities and ameliorate disabilities.
\end{abstract}

Keywords: Congenital, Disability, Birth Defects, Developmental Disabilities, Prevalence, Child Health, Congenital Abnormalities

Conflicts of Interest: None declared

Funding: Funding support from the University Grants Commission-University with Potential for Excellence Holistic area "Translation Research in the Health of Women and Children".

\section{*This work has been published under CC BY-NC-SA 1.0 license.}

Copyright $\odot$ Iran University of Medical Sciences

Cite this article as: Ansari H. Population prevalence of congenital disabilities among children aged 0-2 years resident in urban slums of Pune, India. Med J Islam Repub Iran. 2021 (15 Sep);35:118. https://doi.org/10.47176/mjiri.35.118

\section{Introduction}

Non-fatal birth defects and developmental disabilities are the most significant causes of childhood disabilities (1). Global averages indicate that birth defects affect three

Corresponding author: Dr Humaira Ansari, humairahusnahuma@gmail.com

${ }^{1 .}$ School of Health Sciences, Savitribai Phule Pune University, Pune 411007, India percent of births (2). In India, a systematic review reported that the national prevalence of congenital anomalies was 184.48 per 10000 births (3). Musculoskeletal anoma-

\section{$\uparrow$ What is "already known" in this topic:}

The early years have been identified as a crucial period for the growth and development of children. Birth defects and developmental disabilities are the most important causes of congenital disabilities in children that manifest by the age of 2 years.

$\rightarrow$ What this article adds:

The data suggest that the prevalence of birth defects and congenital disabilities are significant in urban slums in the age group of 0-2 years. As a public health problem, a stepped-up initiative for community awareness is required in order to ameliorate the impact of disabilities through early intervention. 
lies (mainly talipes equinovarus) were the highest among live births. A cohort study determined the birth prevalence of congenital anomalies as 230.51 per 10000 births, of which 168.44 per 10000 births were live-born (4). The study reported that $55 \%$ of the live-born presented with a disability or disabling conditions (arising due to common conditions such as talipes equinovarus, orofacial cleft, scoliosis, Down syndrome and others) (4). Developmental disabilities affect $17 \%$ of children, of which three percent have severe disabilities (5). Their prevalence in India has been reported to be $1.8-2.2 \%$ (6). Data on childhood disabilities are available primarily from the decadal Census. The Census 2011 identifies a significant magnitude of 1.2 million disabled children under the age of five years. The data enumerated there were 250000 blind children, 350 000 children with hearing impairment, 50000 children with mental retardation, 30000 with speech impairment and 1.1 million children with locomotor impairment (6). The Census data, however, does not include data on the time of onset of the disability, that is, whether the disability is congenital (since birth) or acquired (arising after birth). The only available data on congenital disability is available from the National Sample Survey 2018, Disabled persons in India (7). This survey identified that the prevalence of disability was $2.3 \%$ in rural areas and $2.2 \%$ in urban areas. Around $28.3 \%$ of the disabilities were present since birth (7). However, there is no recent data on the contribution of birth defects and developmental disabilities to this magnitude of childhood disabilities in India. Therefore the first objective of our study was to determine the prevalence of congenital disabilities in the community. We also collected data on selected risk factors for these conditions in children in the age group of $0-2$ years resident in slums of Pune. Our study focused on the age group of 0-2 years as the disabling impact of congenital disabilities manifests by this period. Although the Rashtriya Bal Swasthya Karyakram (8) has an ongoing early screening and intervention program for birth defects and developmental disabilities, diagnosis in the private sector and the financial burden of specialized medical management may result in non-compliance and discontinuation of treatment $(2,9)$. Therefore the second objective of our study was to determine the number of clinically diagnosed cases that had accessed treatment.

\section{Methods}

This cross-sectional study was set in urban slums of Pune city, India. Pune is divided into 14 administrative wards. A list of registered and unregistered slums was obtained from the Pune Municipal Corporation and two slums were randomly selected to give a total of 28 slums. Slums were selected using the cluster sampling method. In the next step, thirty children were randomly selected from each slum by identifying the center of the slum and selecting every fifth house to the right having a child under two years of age, until the sample size of 30 children from each slum and a total sample size of 840 was completed. Children were included in the study if they were less than two years of age and permanent residents of the slum. The caregivers were informed about the study and informed consent was obtained from parents/caregivers prior to the interview. The study was initiated after the approval of the institutional ethics committee.

Data was collected through a pretested and validated questionnaire. The questionnaire available in English was translated into the Marathi language and back-translated. The questionnaire was also pilot tested on 88 caregivers resident in urban slums. After minor corrections, this questionnaire was used for data collection. The questionnaire had three sections. The first section included data on socio-demographic characteristics (age of parents, education, religion, income as determined by presence of a below poverty line (BPL) ration card, occupation, consanguinity, family history of a birth defect or congenital disability, or chronic diseases). The second section collected data on child characteristics (including age, gender, birth weight, time and type of delivery, immunization status, breastfeeding status). Immunization, birth weight and data on the timing of birth were validated through hospital records available with the caregiver. The third section collected data on the outcome, that is, a diagnosed birth defect and/or a congenital disability. Diagnosed birth defects were defined as clinician diagnosed congenital anomaly, and developmental disability was defined as a disability that was reported to be present since birth, even without a clinical diagnosis and not acquired after illness or injury. Data reported by the respondent was validated through clinical records availlable with the respondent. Data on congenital disabilities were collected through the questionnaire which documented respondent's reports of perception of any form of locomotor, hearing, speech, visual or cognitive impairment, respondents' perception of time of onset of the disability, and available clinical records. Data were compiled, coded, grouped, and analyzed using Statistical Package for Social Sciences (SPSS) 22. Descriptive analysis was used to describe relationships among variables. The prevalence rate was calculated as the number of children under 2 years of age with the condition per 100 children under 2 years of age. Pearson's chi-square test was used to determine associations, and the level of significance was established at $\mathrm{P}<0.05$. Associations between outcomes of interest and risk factors were expressed as Odds Ratios (OR) at 95\% Confidence Interval $(\mathrm{CI})$.

\section{Results}

Tables 1 and 2 describe the socio-demographic characteristics of the parents. The majority of families belonged to the Hindu religion ( $\mathrm{n}=654,78 \%$ ), followed by Muslims $(\mathrm{n}=184,22 \%)$. Among all families, almost one-fourth $(\mathrm{n}=198,24 \%)$ possessed yellow colored cards indicating BPL status. Consanguineous marriages among parents were seen among $296(35 \%)$ children. Family history of birth defects (congenital heart disease and cleft lip) was reported by $2(0.3 \%)$ respondents (Table 1$)$.

Table 2 shows that majority of mothers $(\mathrm{n}=716,85 \%)$ were in the age group of 18-25 years at the time of birth of the child and more than half had studied up to high school or intermediate level $570(68 \%)$. In contrast, $87(10 \%)$ mothers were illiterate. Almost all mothers were home- 


\begin{tabular}{lc}
\multicolumn{2}{l}{ Table 1. Socio-demographic characteristics $(\mathrm{n}=840)$} \\
\hline Socio demographic characteristics & $\mathrm{n}(\%)$ \\
\hline Religion & $654(77.8)$ \\
Hindu & $184(22)$ \\
Muslim & $2(0.2)$ \\
Others & \\
Below poverty line status & $198(24)$ \\
Yes & $502(60)$ \\
No & $140(16)$ \\
Not available & \\
Consanguineous marriage & $296(35)$ \\
Yes & $544(65)$ \\
No & \\
Family history of birth defects & $2(0.3)$ \\
Yes & $838(99.7)$ \\
No
\end{tabular}

Table 2. Characteristics of parents $(\mathrm{n}=840)$

\begin{tabular}{lc}
\hline Characteristics of mother & $\mathrm{n}(\%)$ \\
\hline Age at birth of the child & $716(85)$ \\
$18-25$ & $121(14)$ \\
$26-30$ & $3(1)$ \\
$>30$ & \\
Education & $87(10)$ \\
Illiterate & $183(22)$ \\
Primary, middle school & $570(68)$ \\
High school, graduate & \\
Occupation & $816(97)$ \\
Homemakers/unemployed & $18(2)$ \\
Unskilled, semiskilled & $6(1)$ \\
Skilled, shop owner, professional & \\
Characteristics of father & \\
Age at birth of child & $415(49)$ \\
18-25 & $392(47)$ \\
26-30 & $33(4)$ \\
$>30$ & \\
Education & $81(10)$ \\
Illiterate & $162(19)$ \\
Primary, middle school & $597(71)$ \\
High school, graduate & \\
Occupation & $28(3)$ \\
Homemakers/unemployed & $396(47)$ \\
Unskilled, semiskilled & $416(50)$ \\
Skilled, shop owner, professional &
\end{tabular}

makers $(\mathrm{n}=816,97 \%)$. Almost half the fathers $(\mathrm{n}=415$, $49 \%$ ) were in the age group of $18-25$ years at the time of birth of the child, and the majority $(n=807,96 \%)$ of fathers were below 30 years of age. More than half of them had studied up to high school or intermediate level 597 $(71 \%)$. While $81(10 \%)$ fathers were illiterate. Approximately half of them were engaged in unskilled or semi-skilled work $(\mathrm{n}=396,47 \%)$. About $28(3 \%)$ fathers were unemployed (Table 2).

\begin{tabular}{lc} 
Table 3. Characteristics of children $(\mathrm{n}=840)$ & \\
\hline Characteristics of children & $\mathrm{n}(\%)$ \\
\hline Age of child & \\
$0-12$ months & $495(59)$ \\
$13-18$ months & $345(41)$ \\
Gender & \\
Male & $439(52)$ \\
Female & $401(48)$ \\
Type of delivery & \\
Normal & $614(73)$ \\
Cesarean section & $226(27)$ \\
Birth weight & \\
Low birth weight $(<2500)$ & $102(12)$ \\
Normal birth weight $(\geq 2500)$ & $664(79)$ \\
Data not available & $74(9)$ \\
Time of delivery & $61(7)$ \\
Preterm & $779(93)$ \\
Fullterm & \\
Breastfeeding status & $497(59)$ \\
Yes, exclusive & $333(40)$ \\
Yes but not exclusive & $10(1)$ \\
Not breastfed & \\
Immunization status & $740(89)$ \\
Complete & $88(10)$ \\
Partial & $12(1)$ \\
Unimmunized &
\end{tabular}

Table 3 shows the characteristics of children. More than half the children $(\mathrm{n}=495,59 \%)$ were infants, and 439 (52\%) were boys. At birth, $102(12 \%)$ children were low birth weight i.e. $<2500$ grams and $61(7 \%)$ were preterm. Data on birth weight was not available for $74(9 \%)$ of children. Almost one-fourth of the children $(n=226,27 \%)$ were delivered by Caesarean section. More than half were exclusively breastfed for six months $(\mathrm{n}=497,59 \%)$ while $10(1 \%)$ of children were not breastfed at all. The majority of the children were completely immunized $740(89 \%)$ and only $12(1 \%)$ were unimmunized (Table 3 ).

Table 4 shows that the prevalence of congenital disabilities was $1.67 \%$ (95\% CI $0.91-2.78)(14 / 840)$. The prevalence of diagnosed birth defects was $1.19 \%$ (95\% CI 0.57 $2.18)(10 / 840)$. These included 5 children with congenital heart defects, and one each of umbilical hernia, congenital talipes equino varus, hydrocephalus, imperforate anus, and orofacial cleft. The prevalence of developmental disabilities was $0.48 \%(95 \%$ CI $0.13-1.21)(4 / 840)$, of which three children had a locomotor disability (difficulty in standing and walking independently) and one child had a diagnosis of periventricular leukomalacia and had multiple disabilities (locomotor, intellectual and speech impairment).

Table 4. Prevalence of birth defects and congenital disabilities in children 0-2 years of age

\begin{tabular}{lccc}
\hline Outcome & Types & Number of children & Prevalence (\%) \\
\hline Total & Birth defects and developmental disabilities & 14 & $1.67(0.91-2.78)$ \\
Birth defects & Congenital heart defects & 10 & $1.19(0.57-2.18)$ \\
& Congenital talipes equino varus (CTEV) & 5 & $0.60(0.19-1.38)$ \\
& Hydrocephalus & 1 & $0.12(0.00-0.66)$ \\
& Orofacial cleft & 1 & $0.12(0.00-0.66)$ \\
& Imperforate anus & 1 & $0.12(0.00-0.66)$ \\
Developmental disabilities & Umbilical hernia & 1 & $0.12(0.00-0.66)$ \\
& Locomotor disability* & 1 & $0.12(0.00-0.66)$ \\
& Periventricular leukomalacia & 4 & $0.48(0.13-1.21)$ \\
\hline
\end{tabular}

\footnotetext{
*Incomplete diagnosis due to non-compliance to referral
} 


\begin{tabular}{|c|c|c|c|c|}
\hline Characteristics & $\begin{array}{c}\text { Birth defects } \\
\mathrm{n}(\%)\end{array}$ & $\begin{array}{c}\text { No birth defects } \\
\mathrm{n}(\%)\end{array}$ & $\mathrm{p}$ & OR $(95 \% \mathrm{CI})$ \\
\hline \multicolumn{5}{|l|}{ Term of delivery } \\
\hline Preterm & $5(0.6)$ & $58(6.9)$ & 0.045 & $4.34(1.03-18.28)$ \\
\hline Full term & $5(0.6)$ & 772 (91.9) & & Reference \\
\hline \multicolumn{5}{|l|}{ Birth weight } \\
\hline$<2500$ & $7(0.8)$ & $95(11.3)$ & 0.003 & $10.41(2.21-48.38)$ \\
\hline$\geq 2500$ & $3(0.4)$ & $735(87.5)$ & & Reference \\
\hline
\end{tabular}

On univariate analysis (Table 5), children with birth defects were more likely to be premature $(\mathrm{P}=0.045$, $\mathrm{OR}=4.34,95 \% \mathrm{CI}=1.03-18.28)$ and low birth weight $(\mathrm{P}=0.003, \mathrm{OR}=10.41,95 \% \mathrm{CI}=2.21-48.38)$. Among the 10 children with birth defects, six had been taken for treatment (two children with CHD and one child with imperforate anus), three children with CHDs had been advised to wait, and 4 had not sought treatment due to either lack of money or as caregivers reported being unsure of what to do. Among the children with birth defects, two were diagnosed prenatally, seven during infancy and one child was diagnosed between 13-24 months. Out of the four children with disabilities, only one child was on treatment (with periventricular leukomalacia), while the remaining were not taken for treatment.

\section{Discussion}

The early years have been identified as a crucial period for the growth and development of children. Although the child below two years is a critical age group, the contact between the public health system and children of this age is limited to immunization visits and when the child is brought for an illness episode. Currently, there is no program for monitoring early development and child growth. Children of this particular age group do not attend Anganwadis, and thus, congenital disabilities might go unrecognized in this particular age group. In order to address this, the study surveyed a sample of 840 children under two years of age for clinically diagnosed birth defects and developmental disabilities. The data revealed that the prevalence of congenital disabilities was $1.67 \%$, arising primarily due to birth defects $(1.19 \%)$ and developmental disabilities $(0.47 \%)$. Like other studies $(4,10)$, birth defects related to the cardiovascular system constituted the largest number of cases, while other defects identified in this study included common conditions like congenital talipes equinovarus, orofacial cleft, hydrocephalus and imperforate anus. Comparison of the prevalence data from this study with the Indian cohort study (4) showed an identical prevalence of congenital heart defects at $0.6 \%$. This prevalence is an underestimate, suggesting that the majority of diagnoses must be occurring at a later age (4). A significant observation from the current study was the $0.5 \%$ prevalence of developmental disability in children under two years of age, suggesting that 5 out of 1000 children under two years of age are likely to be born with a disability.

The present study identified that only seven out of 14 children had received medical care, while other caregivers had either not sought treatment after diagnosis or had delayed the decision for medical consultation due to eco- nomic reasons. Among the latter was a child with talipes equinovarus. Since 2013, the RBSK program supports the free surgical correction of heart defects, orofacial clefts and treatment of talipes equinovarus (8) but the data from this study shows that there is limited outreach of the service and that there is low awareness about the availability of these services in the community. This observation has also been reported from earlier studies $(11,12)$. Another finding of the study was a strong association between prematurity, low birth weight and birth defects similar to other studies $(10,13,14)$.

The findings of this study indicate that the prevalence of birth defects and congenital disabilities are not insignificant in urban slums. The data suggest a stepped-up initiative for community awareness in order to ameliorate the impact of disabilities through early intervention. The study suggests that a universal screening program for $0-2$ years should be promoted immediately so that early identification will help in early refierral and a better long-term outcome. The identification that the significant risk factors identified in this study are also risk determinants of other adverse pregnancy outcomes indicates that the prevention of congenital disabilities (arising due to birth defects and developmental disabilities) can be undertaken through existing maternal health programs. Improving awareness among the community regardling the effects of consanguineous marriage will go a long way in reducing birth defects and congenital disabilities. The strengths of the study were that it was population-based and was based on clinically diagnosed cases as the outcome. However, undiagnosed cases in the community may be a limitation in this study and lead to an under-estimation of the prevalence.

\section{Conclusion}

Birth defects and developmental disabilities are prevalent in children less than two years of age living in slums. Screening and early intervention for children aged 0-2 years is essential.

\section{Acknowledgement}

The author would like to acknowledge the study participants. Funding support from the University Grants Commission-University with Potential for Excellence Holistic area "Translation Research in the Health of Women and Children" is gratefully acknowledged.

\section{Conflict of Interests}

The author declares that they have no competing interests. 


\section{References}

1. Boyle CA, Cordero JF. Birth defects and disabilities: a public health issue for the 21st century. Am J Public Health. 2005;95:1884-6.

2. Christianson AL, Howson CP, Modell B. Global report on birth defects: The hidden toll of dying and disabled children. New York, USA: March of Dimes, Birth Defects Foundation; 2006. Available from: http://www.marchofdimes.com. [Last accessed on 13th February 2020].

3. Bhide P, Kar A. A national estimate of the birth prevalence of congenital anomalies in India: systematic review and meta-analysis. BMC Pediatr. 2018;18:175.

4. Bhide P, Gund P, Kar A. Prevalence of Congenital Anomalies in an Indian Maternal Cohort: Healthcare, Prevention and Surveillance Implications. PLoS One. 2016;11:e166408

5. Birth defects and developmental disabilities: CDC Activities. Available from https://www.ncsl.org/print/health/CBoyle807.pdf [Last accessed on 13th February 2020].

6. Disabled persons in India. A statistical profile 2016. Ministry of Statistics and Programme Implementation. Government of India. Available from: http://mospi.nic.in/sites/default/files/publication reports/Disabled_persons_in_India_2016.pdf [Last accessed on 13th February 2020].

7. Disabled persons in India. National Sample Survey, 76th round, July December 2018. New Delhi. National Sample Survey Organization. Ministry of Statistics and Programme Implementation. Government of India; 2019. Available from: http://www.mospi.gov.in/sites/default/ files/publication reports/Report 583 Final 0.pdf [Last accessed on 13th February 2020].

8. Rashtriya Bal Swasthya Karyakram Operational Guidelines, Ministry of Health \& Family Welfare. Government of India; 2013. Available from

http://nhm.gov.in/images/pdf/programmes/RBSK/Operational Guideli nes/Operational\%20Guidelines_RBSK.pdf. [Last accessed on 13th February 2020].

9. Kar A. Birth defects in India: Magnitude, public health impact and prevention. JKIMSU. 2014;3:7-16.

10. Taksande A, Vilhekar K, Chaturvedi P, Jain M. Congenital malformations at birth in Central India: A rural medical college hospital based data. Indian J Hum Genet. 2010;16(3):159.

11. Kaur P, Chavan BS, Lata S, Kaur A, Tinku S, Arora Y, Ratnam V. Early intervention in developmental delay. Indian $\mathrm{J}$ Pediatr. 2006;73:405-8

12. Nair MK, Rekha Radhakrishnan S. Early childhood development in deprived urban settlements. Indian Pediatr. 2004;41:227-38.

13. Mekonen HK, Nigatu B, Lamers WH. Birth weight by gestational age and congenital malformations in Northern Ethiopia. BMC Pregnancy Childbirth. 2015;15(1):76.

14. Kumar R, Bhave A, Bhargava R, Agarwal GG. Prevalence and risk factors for neurological disorders in children aged 6 months to 2 years in northern India. Dev Med Child Neurol. 2013;55:348-56. 